\title{
LYAPUNOV INEQUALITIES FOR TWO-PARAMETRIC QUANTUM HAMILTONIAN SYSTEMS AND THEIR APPLICATIONS
}

\author{
YOUSEF GHOLAMI
}

Abstract. This paper deals with study of the two-parametric quantum Hamiltonian systems. The main objective in our study is Lyapunov inequalities of the two-parametric quantum Hamiltonian systems. In this paper, we first define two-parametric quantum analogous of the Leibniz rule, Cauchy-Schwarz and Holder inequalities and consequently as theoretical part of our main results, by the use of new Leibniz rule and Cauchy-Schwarz inequality on the considered Hamiltonian systems we obtain corresponding Lyapunov inequalities. Applicability of the obtained Lyapunov inequalities is examined by presenting a disconjugacy and at the same time a nonexistence criterion for the related Hamiltonian systems.

Mathematics subject classification (2010): 05A30, 37K05, 81Q80, $26 \mathrm{D} 15$.

Keywords and phrases: Quantum calculus, Hamiltonian system, Lyapunov inequality, disconjugacy, nonexistence.

\section{REFERENCES}

[1] T. Abdeljawad, J. Alzabut, D. Baleanu, a generalized q-fractional Gronwall inequality and its applications to nonlinear delay q-fractional difference systems, J. Inequal. Appl. 2016, no. 1, (2016), pp. 1-13.

[2] C. D. Ahlbrandt, Hamiltonian systems on time scales, J. Math. Anal. Appl. 250, (2000), pp. 561578.

[3] George A. Anastassiou, Multivariate Lyapunov inequalities, Appl. Math. Lett. 24, (2011), pp. $2167-2171$.

[4] A. Chidoun, D. F. M. Torres, A generalized Lyapunov's inequality for a fractional boundary value problem, J. Comput. Appl. Math. 312, no. 1, (2017), pp. 192-197.

[5] S. Dhar, Q. Kong, M. MCCABE, Fractional boundary value problems and Lyapunov-type inequalities with fractional integral boundary conditions, Electron. J. Qual. Theory Differ. Equ., (2016), no. 43, pp. 1-16.

[6] Rui A. C. FERreira, On a Lyapunov-type inequality and the zeros of a certain Mittag-Leffler function, J. Math. Anal. Appl. 412, (2014), 1058-1063.

[7] K. Ghanbari, Y. Gholami, New classes of Lyapunov type inequalities of fractional $\Delta$-difference Sturm-Liouville problems with applications, Bull. Iranian Math. Soc. 43, no. 2, (2017), pp. 385-408.

[8] Y. Gholami, K. Ghanbari, New class of conformable derivatives and applications to differential impulsive systems, SeMA 75, no. 2, (2018), pp. 305-333.

[9] J. R. GREAF, S. HEIDAR KHANI, L. KONG, Infinitely many periodic solutions to a class of perturbed second-order impulsive Hamiltonian systems, Differ. Equ. Appl. 9, no. 2, (2017), pp. 195-212.

[10] G. Sh. Guseinov, B. Kaymakçalan, Lyapunov inequalities for discrete linear Hamiltonian systems, Comput. Math. Appl. 45, (2003), pp. 1399-1416.

[11] G. Sh. Guseinov, A. ZAFer, Stability criteria for linear periodic impulsive Hamiltonian systems, J. Math. Anal. Appl. 335, (2007), pp. 1195-1206.

[12] P. Hartman, Ordinary Differential Equations, John Wiley and Sons, New York, (1964).

[13] F. H. JACKSON, A Generalisation of the Functions $\Gamma(n)$ and $x^{n}$, Proc. R. Soc. Lond. 74, (1905), pp. $64-72$. 
[14] F. H. JACKSON, On q-Functions and a certain difference operator, Transactions of the Royal Society of Edinburgh 46, no. 2, (1909), pp. 253-281.

[15] F. H. JACKSON, q-Difference equations, Am. J. Math. 32, (1910), pp. 305-314.

[16] V. KaC, P. Cheung, Quantum calculus, Springer, 2001.

[17] Z. KAYAR, A. ZAFER, Matrix measure approach to Lyapunov-type inequalities for linear Hamiltonian systems with impulse effect, J. Math. Anal. Appl. 440, no. 1, (2016), pp. 250-265.

[18] A. M. Lyapunov, The general problem of the stability of motion, Int. J. Control 55, no. 3, (1992), pp. 521-790, http://www.tandfonline.com/toc/tcon20/55/3.

[19] P. Nuionou SADJAnG, On the fundamental theorem of $(p, q)$-calculus and some $(p, q)$-Taylor formulas, arXiv:1309.3934v1, (2013).

[20] D. O'REGAN, B. SAMET, Lyapunov-type inequalities for a class of fractional differential equations, J. Inequal. Appl. 2015, 2015:247.

[21] M. E. H. ISMAIL, D. W. StAnTON, q-Series from a contemporary perspective, American Mathematical Society, (2000).

[22] X. H. TANG, M. ZhAng, Lyapunov inequalities and stability for linear Hamiltonian systems, J. Differential Equations 252, (2012), pp. 358-381.

[23] X. H. TANG, Q. M. ZhANG, M. ZhANG, Lyapunov-type inequalities for the first-order nonlinear Hamiltonian systems, Comput. Math. Appl. 62, (2011), pp. 3603-3613.

[24] A. ZAFER, Discrete linear Hamiltonian systems: Lyapunov type inequalities, stability and disconjugacy criteria, J. Math. Anal. Appl. 396, (2012), pp. 606-617. 